\title{
Two-Dimensional Distribution of Light Hydrocarbons: Results From the STRATOZ III Experiment
}

\author{
J. RUDOLPH
}

Institut für Atmosphärische Chemie, Kernforschungsanlage Jülich GmbH, Jülich, Federal Republic of Germany

During the STRATOZ III fights in June 1984, about 120 whole-air samples were collected and analyzed later on in the laboratory for several atmospheric trace components, including light hydrocarbons. The STRATOZ III mission consisted of 21 flight segments and covered a latitude range from $70^{\circ} \mathrm{N}$ to $60^{\circ} \mathrm{S}$ and altitudes up to $12 \mathrm{~km}$. The results of these measurements were used to construct latitude-altitude profiles in the form of isolines for ethane, ethene, acetylene, propane, propene, $n$-butane, isobutane, $n$-pentane, and isopentane. These results are compared with the latitudinal cross sections obtained during a previous, very similar flight mission (STRATOZ II) in May-June 1980. Also, the few published latitudinal or vertical profiles for these nonmethane hydrocarbons (NMHCs) are used for a comparison. The two-dimensional distributions for the longer-lived NMHCs, especially ethane and to some extent also propane and acetylene, are reasonably representative, even on a global scale. The high variability of the short-lived NMHCs, the $C_{4}$ and $C_{5}$ alkanes, and the light alkenes, prevents the determination of representative two-dimensional distributions for these species. The distributions of these short-lived compounds give at best an extremely rough idea on the distributions and should in general be considered as descriptions of a given momentary situation. These latitude-altitude profiles indicate the existence of fast mechanisms for vertical mixing in the troposphere. The observation of high mixing ratios of short-lived hydrocarbons in the middle and upper troposphere proves the existence of vertical mixing processes with a time scale comparable to, or even shorter than, the atmospheric lifetime of these reactive NMHCs. As a consequence, there exist several regions, even above the boundary layer, with NMHC mixing ratios high enough to make them important participants in the atmospheric photochemical reaction cycles.

\section{INTRODUCTION}

In June 1984 our institute had the opportunity to participate in the STRATOZ III flight of a Caravelle research aircraft, which was organized by the French Centre d'Essais en Vol at Bretigny sur l'Orge and the Etablissement d'Etudes et de Recherches Metéorolgiques (EERM) at Toulouse, France.

The STRATOZ III mission consisted of 21 individual flight sections and covered a latitude range from nearly $70^{\circ} \mathrm{N}$ to $60^{\circ} \mathrm{S}$ (Figure 1). On the average, each individual flight section was about $3000 \mathrm{~km}$ long. This allowed measurement of vertical profiles during landing or takeoff, with an average distance between the vertical profiles of $11^{\circ}-12^{\circ}$ latitude. In this paper the results from measurements of the $\mathrm{C}_{2}-\mathrm{C}_{5}$ hydrocarbons during the STRATOZ III flights are presented.

An experiment nearly identical to the STRATOZ III flight had already been conducted in April-May 1980. The results of this previous STRATOZ flight were published by Ehhalt et al. [1985]. They indicated the existence of systematic latitudinal gradients for several nonmethane hydrocarbons (NMHCs) at all altitudes, but they also indicated a good deal of variability, which was ascribed to transport mechanisms. Especially, the occurrence of high-NMHC mixing ratios in the upper troposphere was interpreted in terms of fast mechanisms of upward transport.

The measurements made during STRATOZ III add to the very sparse data sets on the latitudinal and altitudinal distributions of NMHCs in the background atmosphere. Even more important is the question of whether the occurrence of high-NMHC mixing ratios in the upper troposphere, as observed during STRATOZ II, is a common feature for altitude-

Copyright 1988 by the American Geophysical Union.

Paper number 8D0154.

0148-0227/88/008D-0154\$05.00 latitude cross sections of NMHCs or is only due to special meterological conditions prevailing during the STRATOZ II flights.

Furthermore, it should be possible to gather a reasonable idea on the systematic latitude-altitude distributions of some NMHCs and their variability.

\section{EXPERIMENTAL Procedure}

The air samples were collected in evacuated stainless steel containers of $2 \mathrm{dm}^{3}$ volume. The bottles were shipped back to the laboratory and analyzed for their contents of a number of trace gases, including the light NMHCs. The time elapsed between sample collection and measurement was about 2-3 months. The sample containers allow storage of the air samples for these periods without any detectable change in the mixing ratios of the light NMHCs. Details of the sample containers and their preparation are given by Rudolph et al. [1981a].

Fifteen sample containers were connected to a common stainless steel inlet line. The inlet line led to a stainless steel air intake tube mounted on top of the airplane's cabin. This intake tube extended about $10 \mathrm{~cm}$ above the boundary layer of the airplane to avoid the risk of collecting air samples contaminated by the airplane itself. For the same reason, the air intake was positioned forward of the airplane's engines. During the flights the air inlet line was flushed with outside air at a rate of $2 \mathrm{~m}^{3} \mathrm{~h}^{-1}$ to minimize all wall effects, such as contaminations, adsorbtion losses, or memory effects. During landing, the stay at the airport, and takeoff, the inlet line was flushed with clean air at a flow rate of $1 \mathrm{dm}^{3} \mathrm{~h}^{-1}$ in reverse direction. This avoided the risk of contaminating the air intake system by the sometimes heavily polluted air at the airports.

The air samples were analyzed by gas chromatography. The 


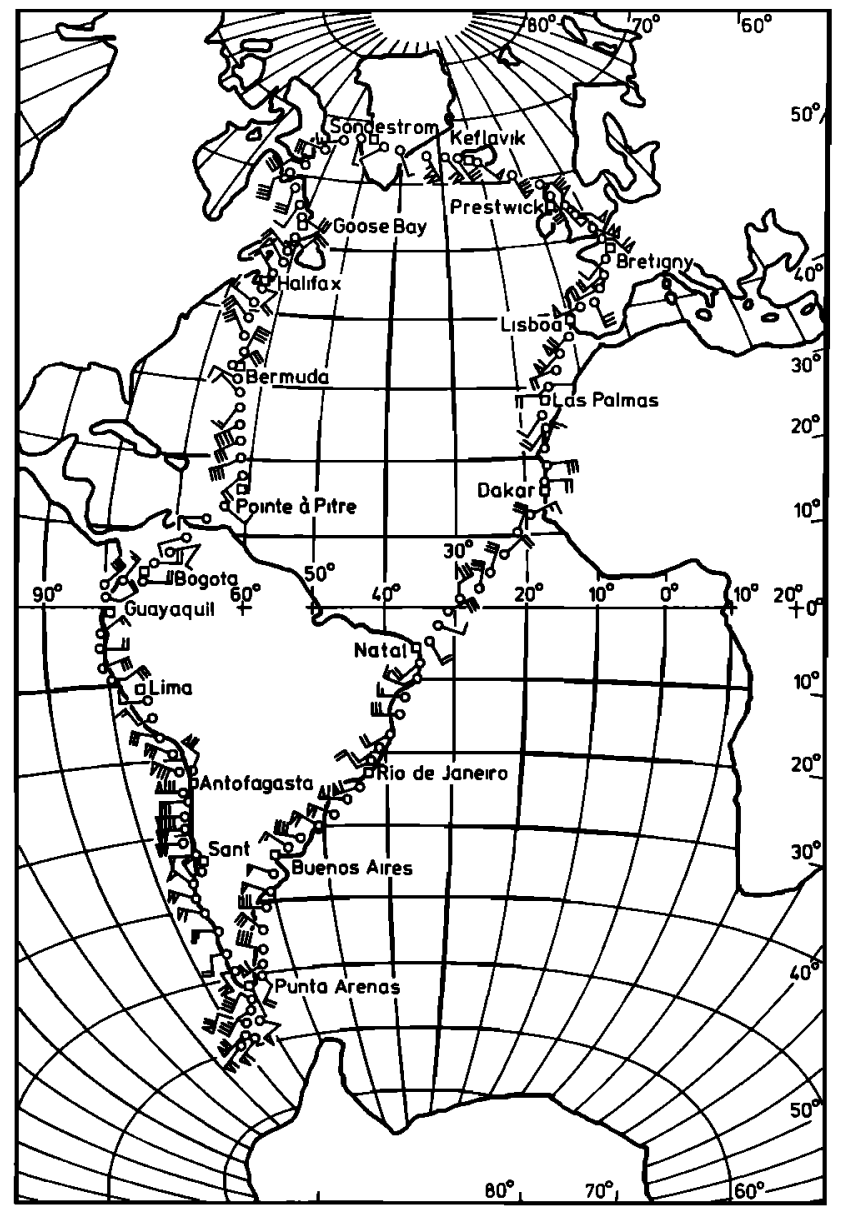

Fig. 1. Flight track of the Caravelle 116 airplane during STRATOZ III. The wind vanes indicate the wind direction and velocity averaged over 20 -min intervals.

trace gases were preconcentrated at $80 \mathrm{~K}$ on a small precolumn ( $20 \mathrm{~cm}$ long, $2 \mathrm{~mm}$ ID) packed with porous glass beads. The lighter fraction $\left(<C_{4}\right)$ of the preconcentrated sample was separated on a column ( $0.8 \mathrm{~mm}$ ID, $6 \mathrm{~m}$ long) packed with Porapack $Q$. The heavier fraction $\left(>C_{4}\right)$ was analyzed on a 60-m DB-1 fused silica capillary column. For optimum sensitivity and selectivity, a combination of a photoionization detector, an electron capture detector, and a flame ionization detector in series was used. The detection limits for the $\mathrm{C}_{2}-\mathrm{C}_{5}$ hydrocarbons were in the range of $5-10 \mathrm{ppt} C$. The reproducibility of the results ranged around $5-10 \%$. The measurements were calibrated with standards of hydrocarbon mixing ratios between 0.2 and $5 \mathrm{ppb}$. These standards were prepared by two- or three-step static dilution of the pure hydrocarbons with purified synthetic air. The linearity of the measurements was confirmed by tests with diluted atmospheric air samples. The accuracy of the calibration procedure is estimated to be $20-30 \%$.

Laboratory and field tests confirmed that neither the sampling procedure nor the gas chromatographic analyses caused an detectable changes in the sample composition. A detailed description of the analytical technique is given by Rudolph et al. [1986].

\section{Results}

About 120 whole-air samples were collected during the 21 individual flights of the STRATOZ III mission. The flights began on June 4, 1984, at Bretigny sur l'Orge ( $30 \mathrm{~km}$ south of Paris, France), went northward to Iceland and Greenland, then southward along the east coast of North America and the west coast of South America to Punta Arenas in southern Chile. The plane returned along the east coast of South America and the west coast of Africa back to Europe. The flights ended on June 26 at Bretigny sur l'Orge. The flight route, including the airports for stopovers, is shown in Figure 1. The maximum altitudes for the flights were $11-12 \mathrm{~km}$. In order to minimize the effect of local sources at the airports or in the vicinity of the airports, the airplane stayed, during most flights, at an altitude between 1 and $2 \mathrm{~km}$ for about $15 \mathrm{~min}$ after takeoff. This allowed collection of air samples at low altitudes at a distance of $100-150 \mathrm{~km}$ from the airports.

The sample collection pattern is shown in Figure 2 as function of latitude and altitude. Some of the samples were collected in the lowest stratosphere or in the range of the tropopause. These samples are indicated by triangles. The stratospheric samples were identified by in situ measurements of the temperature and ozone profiles.

From the mixing ratios of the different NMHCs meridional cross sections were constructed in the form of isolines. The flight routes for the southbound (Sondrestrom-Punta Arenas) and for the northbound flights (Punta Arenas-Bretigny and Bretigny-Sondrestrom) were quite different. Therefore separate altitude-latitude profiles were constructed for these two flight legs. We did not try to interpolate between the two parts of the northbound flights (Punta Arenas-Bretigny and Bretigny-Sondrestrom). Between the takeoff from Bretigny and the landing at Bretigny, 3 weeks had elapsed. In the meantime the meteorological situation had changed [cf. $R \boldsymbol{u}$ dolph et al., 1987]. The meridional cross section for ethane, propane, $i$-butane, $n$-butane, $i$-pentane, $n$-pentane, ethene, propene, and acetylene are shown in Figure 3.

The spacing of the isolines for the various hydrocarbons are about a factor of 2 in concentration, with the exception of ethane, which showed a lower variability than the other NMHCs. Such a presentation of two-dimensional distributions on the basis of 120 measurements for each hydrocarbon species can only show the most important features. Furthermore, it should be remembered that the observed altitude-latitude profiles represent only a momentary picture of the trace gas distribution and not necessarily a well-defined average.

Presenting the data as meridional cross sections allows a good presentation of rather large numbers of data and provides a convenient basis for a comparison of the individual two-dimensional profiles with each other and with the results from the previous measurements during the STRATOZ II flights in 1980.

\section{General Features}

\section{Discussion}

The shape of the altitude-latitude profiles for the different NMHCs is determined by three factors: the atmospheric transport processes, the source, and the sink distribution. The different NMHCs were measured simultaneously. Thus atmospheric transport conditions for all the NMHCs are identical. The main sources for atmospheric $\mathrm{C}_{2}-\mathrm{C}_{5}$ hydrocarbons are engine exhaust, evaporation losses of fuel or crude oil, natural gas losses, biomass burning (forest fires, agricultural waste burning, burning of fuel wood, slash and burn argiculture, etc.) microbial production, and emissions from foliage and from the oceans [Ehhalt and Rudolph, 1984]. Minor sources are oil and 
coal burning, losses from industrial processes, and evaporation of solvents. The emission ratios for the different NMHCs vary from source to source. The dominating atmospheric loss mechanism for light NMHCs is the reaction with $\mathrm{OH}$ radicals. For alkenes the reaction with ozone also has to be taken into account. The rate constants for the reactions of the various light NMHCs with $\mathrm{OH}$ radicals differ by orders of magnitudes, and consequently, the atmospheric lifetimes of the $\mathrm{C}_{2}-\mathrm{C}_{5}$ hydrocarbons differ [cf. Rudolph and Ehhalt, 1981]. It should also be considered that the atmospheric $\mathrm{OH}$ radical concentration is a function of season, latitude, and altitude [cf. Volz et al., 1981]. Thus the atmospheric lifetime of each hydrocarbon is a function of latitude, altitude, and season. The atmospheric lifetime of the $\mathrm{C}_{2}-\mathrm{C}_{5}$ hydrocarbons is a factor of roughly 3 shorter at low latitudes than on the global average [Rudolph and Ehhalt, 1981].

We can expect that several of the different NMHCs will have some similarities in their two-dimensional cross sections, but we can also expect a good deal of variability, especially for the short-lived NMHCs with atmospheric lifetimes of a few days or even less.

Indeed, the two-dimensional distributions of the alkanes have some pronounced features in common. These features are the existence of a region of high mixing ratios at mid and high northern latitudes, which extends from altitudes of 1-2 km up to the tropopause, a general decrease in mixing ratios between mid and low northern or southern latitudes, the occurrence of a few smaller areas with increased mixing ratios at low latitudes, partly in the form of isolated maxima, and a difference in the mixing ratios between the northbound and the southbound flights at $30^{\circ}-50^{\circ} \mathrm{N}$, with lower mixing ratios for the northbound flights. However the two-dimensional profiles of the various NMHCs still are different in several aspects. Not only do the absolute levels of the mixing ratios differ, but also the relative change between the highest and lowest mixing ratios of the individual NMHCs in the troposphere differs by orders of magnitude, e.g., this difference is less than an order of magnitude for ethane but nearly a factor of 500 for isopentane.

Furthermore, the latitude range where we can observe the strongest north-south gradient depends on the individual NMHC species during the southbound flights. The most pronounced decrease in mixing ratios is observed at very low latitudes for $\mathrm{C}_{2} \mathrm{H}_{6}$ and around $30^{\circ}-40^{\circ} \mathrm{N}$ for $i$-pentane. The

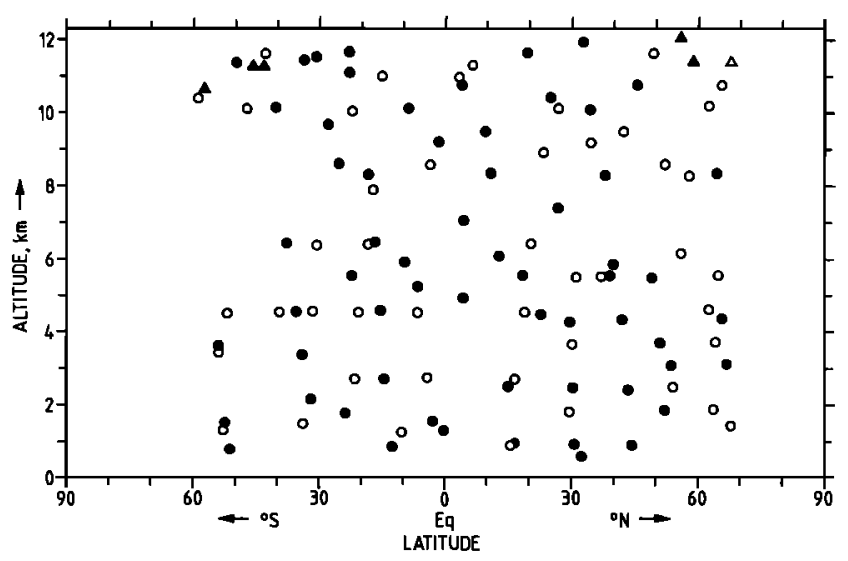

Fig. 2. Two-dimensional collection pattern for whole-air samples and NMHC measurements during the STRATOZ III flights. Solid symbols indicate southbound flights; open symbols, northbound flights. Triangles indicate that the sample was collected in the tropopause range or in the lowest stratosphere. reasons for these differences are obviously the different source distributions and the differing atmospheric lifetimes for the various NMHCs.

\section{Ethane and Propane}

The known major sources for ethane are natural gas losses, biomass burning, and emissions from the oceans. Less important are emissions from foliage, microbial production, and engine exhaust [Ehhalt and Rudolph, 1984]. With an average atmospheric lifetime of 2 months [Rudolph and Ehhalt, 1981], ethane is the longest-lived of the NMHCs.

At mid and high northern latitudes, the ethane mixing ratios are around $1.5-2 \mathrm{ppb}$, sometimes even exceeding $2 \mathrm{ppb}$. With the exception of a single ethane measurement of $3.2 \mathrm{ppb}$, no ethane mixing ratios exceeding $3 \mathrm{ppb}$ were observed. During the northbound flights, for the latitude range below $50^{\circ} \mathrm{N}$ the ethane mixing ratios at all altitudes are lower than $1.5 \mathrm{ppb}$, sometimes even below $1.0 \mathrm{ppb}$. From Figure 1 it can be seen that during the northbound flights between $25^{\circ} \mathrm{N}$ and Lisboa $\left(40^{\circ} \mathrm{N}\right)$ the wind directions indicate that air masses from the Atlantic were sampled during this part of the flights. During June 24-26 a large and very persistent high-pressure system, with its center over Algeria, was observed (see also Rudolph et al. [1987]). This system ranged from south of Tripoli to Dakkar. The wind directions observed during the flight indicate general airflow from the southwest between $20^{\circ}$ and $40^{\circ} \mathrm{N}$. From these observations it seems likely that the sampled air masses originated from lower latitudes over the Atlantic. This is consistent with the observation of relatively low mixing ratios for $\mathrm{C}_{2} \mathrm{H}_{6}$ and $\mathrm{C}_{3} \mathrm{H}_{8}$ between $20^{\circ}$ and $40^{\circ} \mathrm{N}$ during the northbound flights. During the corresponding part of the southbound flights, the sampled air masses originated from over North or Central America. This finding is consistent with the idea that losses of natural gas during production and distribution are significant sources of ethane and propane [Ehhalt and Rudolph, 1984]. Incomplete combustion processes also have to be considered as potential sources for the observed ethane and propane mixing ratios over this area. These types of sources, especially engine exhaust, also emit substantial amounts of acetylene [Ehhalt and Rudolph, 1984]. The corresponding acetylene measurements (Figure $3 g$ ) show quite low acetylene mixing ratios, in the range of a tenth of a part per billion or even less. This essentially rules out incomplete combustion, and especially engine exhaust, as sources for the ethane (and propane) levels observed between $25^{\circ}$ and $40^{\circ} \mathrm{N}$ during the southbound flights.

The southern hemispheric ethane mixing ratios are a factor of 5 lower in general than in the northern hemisphere. It is interesting that in the southern hemisphere the ethane mixing ratios decrease with increasing latitude. At both high northern and high southern latitudes we can see a decrease in the ethane mixing ratios above $10 \mathrm{~km}$. These samples were collected in the lowest stratosphere or in the tropopause regions (see Figure 2). This result agrees with the observations of $\boldsymbol{R u}$ dolph et al. [1981b] and Cronn and Robinson [1979] that the ethane mixing ratios decrease rapidly with increasing altitude above the tropopause. There is no indication for the existence of a systematic vertical gradient for ethane in the troposphere.

There are small isolated maxima of ethane mixing ratios over the equator at a few kilometers of altitude. This indicates the existence of strong sources for ethane at low latitudes, possibly biomass burning [e.g., Greenberg and Zimmermann, 1984; Greenberg et al., 1984]. However, these regions of elevated ethane mixing ratios at low latitudes are much less pronounced than at mid and high northern latitudes. The obser- 

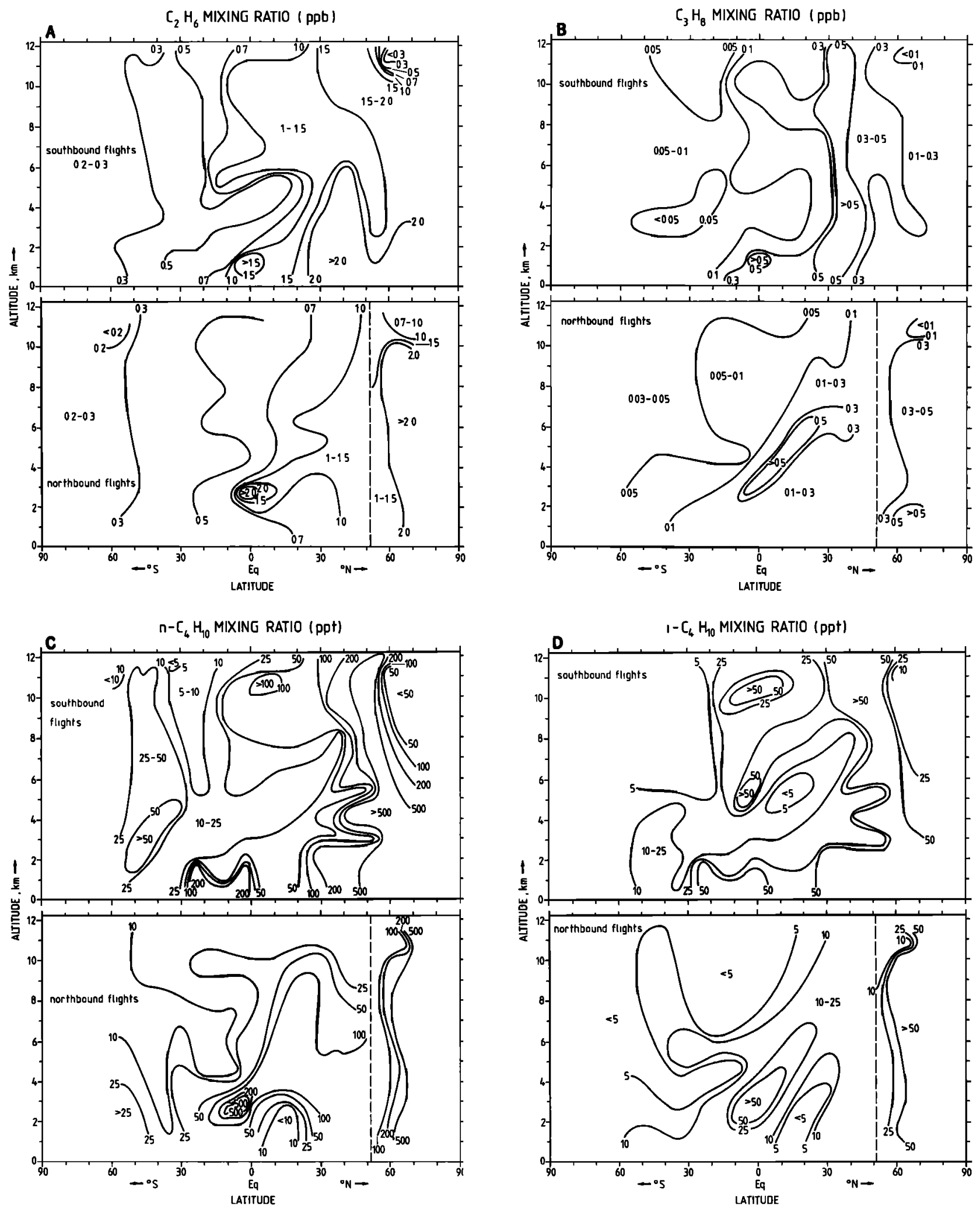

Fig. 3. Two-dimensional distributions of NMHCs derived from the STRATOZ III experiment: (a) ethane; (b) propane; (c) $n$-butane; $(d) i$-butane; $(e) n$-pentane; $(f) i$-pentane; $(g)$ acetylene; $(h)$ ethene; and $(i)$ propene.

vation of maximum ethane mixing ratios at mid and high northern latitudes emphasizes the importance of anthropogenic ethane sources.

The sources for atmospheric propane are mainly natural gas losses, biomass burning, and oceanic emissions, similar to the main ethane sources. However, the total source strength for propane is only about half that of ethane [Ehhalt and Rudolph, 1984]. The average atmospheric lifetime of propane is slightly less than 2 weeks, a factor of about 4 shorter than for ethane. Consequently, the propane cross sections show a more pro- 

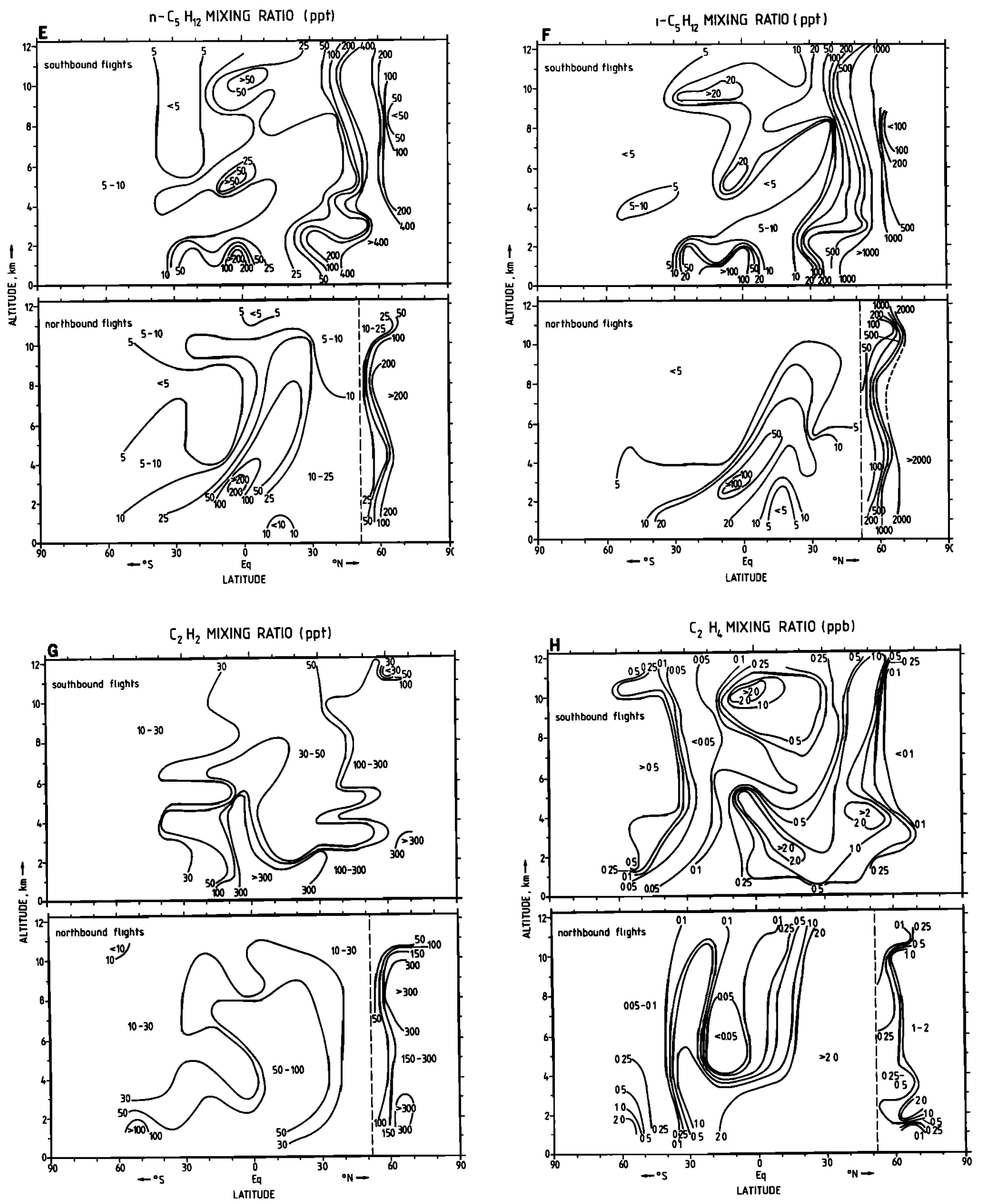

Fig. 3. (continued)

nounced unsystematic variability than the ethane distributions. Apart from this, the shape of the propane and ethane distributions are very similar, but on the average the propane mixing ratios are about a factor of 6 lower.
However, there is one significant exception. The ethane values observed during the southbound flights north of $55^{\circ} \mathrm{N}$ indicate constant, or even increasing, mixing ratios with increasing latitude. In contrast to this, propane shows a signifi- 


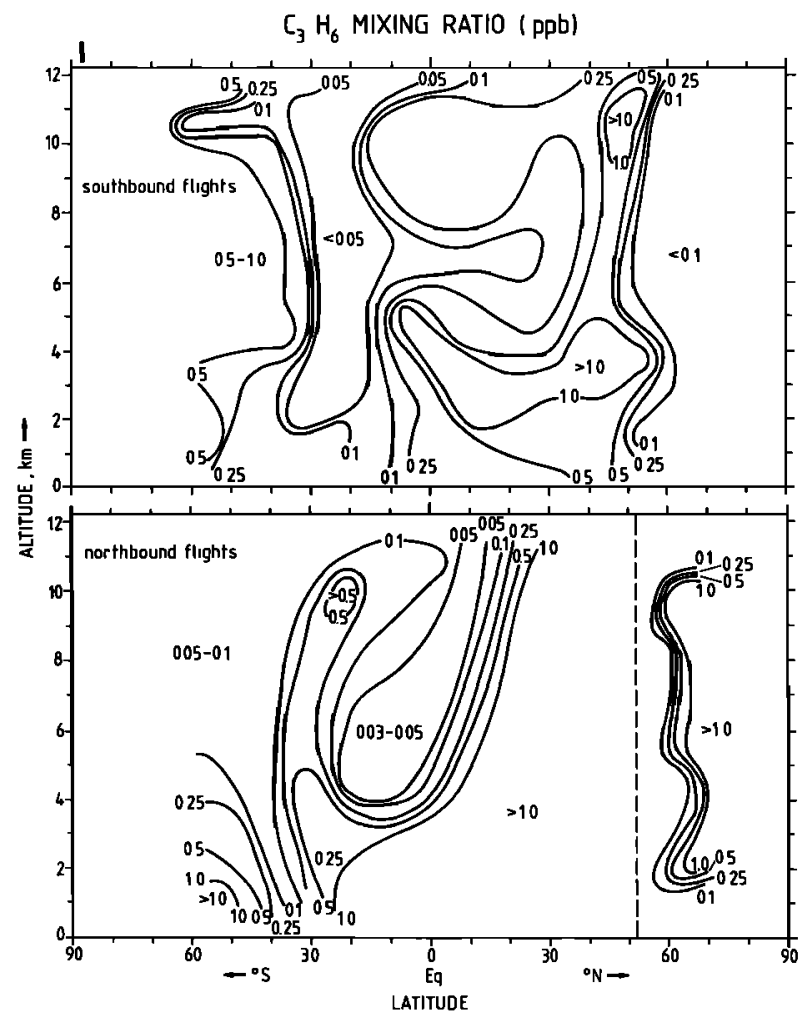

Fig. 3. (continued)

cant decrease with increasing latitude. Most probably, this is due to the (by a factor of 4) faster photochemical oxidation of propane compared to ethane.

\section{Butane}

The average atmospheric lifetime for $n$-butane of about 7 days [Rudolph and Ehhalt, 1981] is by a factor of 2 shorter than for propane. The total source strength of $n$-butane is about $50 \%$ that of propane, and the sources partly differ. In addition to natural gas losses, the main $n$-butane sources are engine exhaust and evaporation losses of fuel [Ehhalt and $\mathrm{Ru}$ dolph, 1984]. Also, oceanic emissions should be considered as important sources for atmospheric n-butane [Bonsang et al., 1988].

Compared to ethane and propane the variability of the $n$ butane distributions is much larger. With a factor of more than 20 between mid northern latitudes and the southern hemisphere, the north-south gradient of $n$-butane is more than twice the gradient for ethane or propane. This decrease in $n$-butane mixing ratios occurs in a narrow latitude belt, mainly between $45^{\circ}$ and $25^{\circ} \mathrm{N}$ for the southbound flights and between $65^{\circ}$ and $50^{\circ} \mathrm{N}$ for the northbound flights. Also, the decrease from $55^{\circ} \mathrm{N}$ toward higher latitudes which was observed during the southbound flights in the high troposphere is much more pronounced for $n$-butane than for propane. This supports our assumption that this decrease is due to the faster photochemical oxidation of the more reactive NMHCs. The southern hemispheric $n$-butane mixing ratios are generally below $25 \mathrm{ppt}$, sometimes even less than $10 \mathrm{ppt}$. There are a few smaller regions with elevated $n$-butane levels, sometimes in the form of isolated maxima.

Some of these maxima at low southern latitudes are quite pronounced. The wind direction during sampling (Figure 1) indicates airflow from tropical South America for these latitudes. This indicates the existence of substantial $n$-butane sources in tropical South America, e.g., biomass burning or plant emissions [cf. Greenberg and Zimmermann, 1984]. Since the flight route followed more or less the coastline of South America, where a number of major cities are located, we cannot rule out the possibility that the sampled air masses were influenced by engine exhaust. However, engine exhaust contains considerably more acetylene than $n$-butane. The regions of elevated $n$-butane do not always correspond with regions of elevated acetylene, and hence we surmise that there are other substantial sources for $n$-butane in tropical South America than automobile emissions.

During the flight along the African west coast, between $25^{\circ}$ and $45^{\circ} \mathrm{N}$, we observe a region of relatively high $n$-butane mixing ratios, exceeding 100 ppt. The wind directions shown in Figure 1 indicate that the sampled air masses originated from over the Atlantic. This agrees with the idea that oceanic emissions are substantial sources for atmospheric $n$-butane [Bonsang et al., 1988]. The observed values for $n$-butane over this region are rather high. This may quite well be due to the existence of a large upwelling zone in the Atlantic off the coast of west Africa with high biological activity [e.g., Fleming, 1986]. Indeed, during the season of the flight, very high phytoplankton concentrations were observed in the Atlantic along the west African coast [Esaias et al., 1986]. Moreover, Bonsang et al. [1988] estimate that the source strength for oceanic $n$-butane emissions is $6 \%$ by volume of the oceanic ethene emissions. The observed ethene mixing ratios over the coast of west Africa are generally above $2 \mathrm{ppb}$ (Figure $3 h$ ). This is consistent with the assumption that the corresponding $n$ butane mixing ratios of $100-200$ ppt are mainly due to oceanic emissions. In addition to this, the relatively low mixing ratios of $\mathrm{C}_{2} \mathrm{H}_{6}, \mathrm{C}_{3} \mathrm{H}_{8}$, and $\mathrm{C}_{2} \mathrm{H}_{2}$ observed simultaneously essentially rule out a major impact of long-range transport from areas with high emissions from engine exhaust or natural gas leakage, e.g., Europe or North America.

The two-dimensional cross sections of $n$-butane, especially for the northbound flights, indicate that on the average the $n$-butane mixing ratios decrease slightly with increasing altitude.

The average atmospheric lifetime of isobutane is nearly the same as for $n$-butane, 7.5 days [Rudolph and Ehhalt, 1981]. Furthermore, atmospheric isobutane has the same main sources as $n$-butane. However, the emission rates of isobutane seem to be much lower than for $n$-butane [e.g., Nelson et al., 1983; Bonsang et al., 1988]. Therefore it is not surprising that the shapes of the isobutane cross sections are quite similar to the $n$-butane distributions, but the isobutane mixing ratios are, in general, lower than the values for $n$-butane by a factor of 5-10.

\section{Pentane}

The atmospheric lifetime of $n$-pentane is 5 days, about $30 \%$ shorter than for $n$-butane or $i$-butane. Most of the major atmospheric sources for $n$-pentane are similar to the $n$-butane sources: engine exhaust and evaporation losses of fuel [Ehhalt and Rudolph, 1984] as well as oceanic emissions [Bonsang et al., 1988]. Losses of natural gas are a less important source for n-pentane [Ehhalt and Rudolph, 1984; Nelson et al., 1983]. The $n$-pentane distributions are very similar to the $n$-butane cross sections. However, the difference between mid northern latitudes and low latitudes in the southern hemisphere is slightly 
more pronounced for $n$-pentane than for $n$-butane. This may be due to the shorter atmospheric lifetime of $n$-pentane but also may be due to a somewhat different source distribution. As pointed out by Rudolph and Ehhalt [1981], hydrocarbon emissions associated with fossil fuel consumption, such as engine exhaust, are generally located at higher northern latitudes than emissions due to fuel production, e.g., losses of natural gas from natural gas or oil fields.

Similar, even more pronounced effects can be observed for $i$-pentane. The average atmospheric lifetime of isopentane is about 4 days [Rudolph and Ehhalt, 1981], 20\% shorter than the lifetime of $n$-pentane. The only known major isopentane emissions into the atmosphere are engine exhaust and evaporation losses of fuel. These sources emit about twice as much isopentane as $n$-pentane [Ehhalt and Rudolph, 1984; Nelson et al., 1983]. This is clearly reflected in the two-dimensional distributions of isopentane. The difference in mixing ratios between mid northern and mid southern latitudes is more than 2 orders of magnitude. Apart from the considerably stronger gradients, the $i$-pentane distributions are qualitatively similar to the distributions of the other $\mathrm{C}_{4}$ and $\mathrm{C}_{5}$ alkanes.

\section{Acetylene}

The dominant sources for atmospheric acetylene are engine exhaust and biomass burning [Ehhalt and Rudolph, 1981]. Rudolph and Ehhalt [1981] calculated an average atmospheric lifetime for acetylene of 110 days, based on the rate constants for the reaction of acetylene with $\mathrm{OH}$ radicals published by Davis et al. [1977]. With the improved, larger rate constants published by Michael et al. [1980], a much shorter average atmospheric lifetime for acetylene, of only 3 weeks, is obtained.

The latitude-altitude cross sections show the highest acetylene mixing ratios at mid and high northern latitudes, which fully agrees with the geographical distribution of the largest acetylene source, engine exhaust.

For the southbound flights we also observe a region of substantially elevated acetylene mixing ratios (exceeding 300 ppt) at low altitudes between $30^{\circ} \mathrm{N}$ and $10^{\circ} \mathrm{S}$. Toward higher southern latitudes the acetylene mixing ratios observed below $4 \mathrm{~km}$ altitude decrease by nearly an order of magnitude. South of $35^{\circ} \mathrm{S}$ the acetylene values are around 10-30 ppt. As can be seen from Figure 1, the decrease in the acetylene levels between $10^{\circ}$ and $35^{\circ} \mathrm{S}$ coincides with a change in the origin of air masses from continentally influenced to oceanic air masses. Similar observations can be made for the northbound flight legs along the South American and African coast. During these parts of the flights with prevailing offshore winds, elevated acetylene mixing ratios were found at low altitudes. A possible source for atmospheric acetylene at these low latitudes is biomass burning. But also, engine exhaust from the more densely populated coastal areas of tropical Africa and South America cannot be excluded.

\section{Ethene and Propene}

The latitude-altitude distributions of ethene and propene differ considerably from the distributions of the alkanes and acetylene. Not only is the unsystematic variability much more pronounced, but also there is no systematic latitudinal gradient. The main ethene sources are oceanic emissions, microbial production in soils, biomass burning, emissions from foliage, and engine exhaust. The global source strength for ethene alone is nearly as large as the source strength of all $\mathrm{C}_{2}-\mathrm{C}_{5}$ alkanes together [Ehhalt and Rudolph, 1984]. However, the atmospheric lifetime of ethene is very short, slightly below 2 days [Rudolph and Ehhalt, 1981].

In view of the short atmospheric lifetime of ethene and the different types of sources, the high variability shown by the ethene mixing ratios is not surprising. The ethene mixing ratios vary between less than $0.05 \mathrm{ppb}$ and more than $2 \mathrm{ppb}$. Surprisingly, the occurrence of high ethene mixing ratios is not restricted to lower altitudes. There are several isolated maxima with ethene mixing ratios above $2 \mathrm{ppb}$, one of them centered at $10 \mathrm{~km}$ altitude. Between $20^{\circ}$ and $50^{\circ} \mathrm{N}$ we observed for the northbound flights a large region of ethene mixing ratios exceeding $2 \mathrm{ppb}$, in very few cases even $6 \mathrm{ppb}$, up to the maximum flight level of the airplane (about 11.5 $\mathrm{km}$ ). A similar observation was made during the southbound flights between $30^{\circ}$ and $40^{\circ} \mathrm{N}$. This band of ethene mixing ratios of more than $1 \mathrm{ppb}$ extends to $11 \mathrm{~km}$ altitude. These observations can only be explained by the existence of fast vertical exchange processes [cf. Ehhalt et al., 1985; Chatfield and Crutzen, 1984; Gidel, 1983].

The sources for atmospheric propene are the same as for ethene; the emission rates for propene and for ethene are of comparable magnitude [Ehhalt and Rudolph, 1984]. The average atmospheric lifetime of propene is very short, only 15 hours [Rudolph and Ehhalt, 1981]. Thus it can be expected that the two-dimensional distributions of ethene and propene will be quite similar. Indeed, the patterns for the isolines of ethene and propene look extremely similar, but the propene mixing ratios are lower on the average by a factor of nearly 2 than the corresponding ethene values.

\section{Comparison With Stratoz II Measurements}

In April-May 1980 the Institut für Atmosphärische Chemie participated in a STRATOZ II flight mission. This flight followed nearly exactly the same flight route as STRATOZ III. During STRATOZ II about 100 measurements of $C_{2}-C_{5}$ hydrocarbons were made. The results of these measurements were published in the form of two-dimensional distributions by Ehhalt et al. [1985]. With respect to the measurements of light NMHCs, the STRATOZ II experiment was nearly identical to the STRATOZ III flights except for a few minor differences. As a result of technical reasons the flight from Goosebay to Halifax went via Montreal. During the northbound flights no samples were collected between $35^{\circ}$ and $50^{\circ} \mathrm{N}$. The absolute calibration of the light alkenes (ethene and propene) was rather uncertain. Thus these mixing ratios are possibly by a factor of 2 too low. Therefore we cannot use the STRATOZ II ethene and propene data for a quantitative comparison with our results. The lower limits of detection for the NMHC measurements were higher than for the measurements made during STRATOZ III. Therefore the two-dimensional distribution from STRATOZ II sometimes only presents upper limits for regions where the STRATOZ III results still allow a more detailed resolution of gradients and structures.

The general characteristics for the distributions observed during STRATOZ II and STRATOZ III are similar. For ethane, propane, and acetylene there are only slight differences between the two flight series. Both the shapes of the twodimensional distributions and the absolute mixing ratios observed during STRATOZ III for these three longer-lived NMHCs agree with the results obtained during the STRATOZ II flights in 1980. For acetylene there exists one major feature in the STRATOZ III data which was not found for STRATOZ II. The upward bulge of increased acetylene 
mixing ratios (exceeding $300 \mathrm{ppt}$ ) at tropical latitudes during the southbound part of STRATOZ III was not observed for STRATOZ II.

The shorter-lived alkanes, $n$-butane, isobutane, $n$-pentane, and isopentane show larger differences. In spite of the considerable unsystematic variability shown by the $i$-butane and $n$-butane distributions, in general, the mixing ratios measured for these compounds during the STRATOZ II flights are comparable to the results from the STRATOZ III flights. With the exception of a few smaller regions, the $n$-butane and $i$-butane mixing ratios at low latitudes and in the southern hemisphere are below 30 and $20 \mathrm{ppt}$, respectively, for the STRATOZ II experiment. This compares well with our results from STRATOZ III. However, at mid and high northern latitudes the results differ. During the southbound flight leg of STRATOZ II, an isolated cell of elevated mixing ratios was found for 9 $\mathrm{km}$ altitude around $50^{\circ}-60^{\circ} \mathrm{N}$. The distributions obtained during STRATOZ III at this latitude show a region of increased mixing ratios from below $2 \mathrm{~km}$ to more than $11 \mathrm{~km}$. The levels for $n$-butane and isobutane in these maxima are similar for both STRATOZ II and III, more than $500 \mathrm{ppt}$ for $n$-butane and more than 70 and $50 \mathrm{ppt}$, respectively, for isobutane. Substantial differences are observed for the northbound flights north of $60^{\circ} \mathrm{N}$. The $n$-butane mixing ratios measured during STRATOZ II are generally below $0.1 \mathrm{ppb}$; during STRATOZ III they partly exceeded $0.5 \mathrm{ppb}$. For $i$-butane this difference is smaller, less than a factor 2 .

Within the expected variability the $n$-pentane and $i$-pentane levels measured during the STRATOZ II flights at low northern latitudes and in the southern hemisphere are generally below $50 \mathrm{ppt}$, often even less than $20 \mathrm{ppt}$, comparable to our results from STRATOZ III. At mid and high northern latitudes the STRATOZ II measurements seldom exceeded 0.1 ppb and are mostly between $50-100$ ppt for $n$-pentane and even lower for $i$-pentane. These values are lower, roughly by an order of magnitude, than the corresponding result from STRATOZ III.

\section{Latitudinal and Vertical Profiles}

No other measurements of combined latitude-altitude distributions of light NMHCs are known to us, but there are a number of studies of the latitudinal distributions of NMHCs at sea level and some studies of the vertical profiles of light NMHCs in the troposphere [Bonsang and Lambert, 1985; Singh and Salas, 1982; Tille et al., 1985; Singh et al., 1986; Cronn and Robinson, 1979; Rasmussen and Khalil, 1982; Rasmussen et al., 1983; Rudolph et al., 1981b, 1982a; Rudolph and Ehhalt, 1981; Blake and Rowland, 1986].

There are also several studies of vertical profiles of NMHCs which were made in the vicinity of major sources, often with the intention of investigating the impact of these sources on the composition or chemistry of the atmosphere [e.g., Fishman et al., 1985; Greenberg and Zimmermann, 1984]. Most of the vertical profiles for light NMHCs published by Tille et al. [1985] and Rudolph et al. [1982a] were measured over continental Europe or otherwise quite close to substantial NMHC sources. However, both Tille et al. and Rudolph et al. included the results of several airplane flights made off the west coast of Ireland. The results of these flights are summarized in Table 1. In our comparison of the STRATOZ III results with latitudinal or vertical distributions from the literature, we have to consider that model calculations and some measurements indicate the existence of systematic seasonal cycles [cf. Isaksen et al., 1985; Kasting and Singh, 1986; Blake and Rowland, 1986]. However, the knowledge of the actual seasonal cycles of the light NMHCs is still very limited. Thus we have to be aware of the problem that in addition to some random variability, systematic seasonal cycles may also cause differences in mixing ratios between the individual series of measurements. It should be noted that the data on the vertical distribution of NMHCs are essentially limited to mid and high northern latitudes.

\section{Ethane}

The largest number of measurement series for NMHCs has been published for ethane. The measurements of Tille et al. [1985] and Rudolph et al. [1982a] off the coast of Ireland $\left(12^{\circ} \mathrm{W}-52^{\circ} \mathrm{N}\right)$ in early June 1981 (Table 1) are in the range from 1.3 to $1.9 \mathrm{ppb}$, with an average of $1.6 \mathrm{ppb}$. In mid-June 1979 , at $44^{\circ} \mathrm{N}$, Rudolph et al. [1981 b] measured ethane mixing ratios slightly below $2 \mathrm{ppb}$ in the free troposphere. Rasmussen et al. [1983] measured values of $1.9-2.3 \mathrm{ppb}$ at $70^{\circ} \mathrm{N}$ for altitudes between 1 and $4 \mathrm{~km}$ and slightly lower values, around $1.4 \mathrm{ppb}$, below $1 \mathrm{~km}$ in May 1982. These data are well within the range of our results from STRATOZ III at middle and high northern latitudes. Also, the ethane mixing ratios of $0.77 \pm 0.3 \mathrm{ppb}$ reported by Cronn and Robinson [1979] for $9^{\circ} \mathrm{N}$ in July 1977 agree very well with our findings for this latitude. However, their results for $37^{\circ} \mathrm{N}$ (April 1977) are, with $1 \pm 0.15 \mathrm{ppb}$, slightly below the corresponding STRATOZ III results. With about $0.7-1.0 \mathrm{ppb}$ in the lower and middle troposphere, Singh et al. [1986] observed even lower values at $40^{\circ} \mathrm{N}$ in August 1984 and slightly higher values of $1.3-1.6 \mathrm{ppb}$ in February 1985.

Considerably higher are the ethane mixing ratios measured by Rudolph et al. [1982b] in late November 1980 (Table 1). These differences in mixing ratios between early summer and winter may be caused by systematic seasonal cycles, as indicated by the ground-level measurements of Blake and Rowland [1986], but the data available for the free troposphere at different seasons are still rather limited.

There are several studies of the latitudinal dependence of the atmospheric ethane mixing ratios, mostly at sea level. Some of these studies coincide in season with the STRATOZ III flights. Rasmussen and Khalil [1982] reported measurements of ethane in air samples collected during the GAMETAG flights in May 1978 in and above the boundary layer. They observed no significant difference between the ethane mixing ratios in and above the boundary layer. At $30^{\circ}-35^{\circ} \mathrm{N}$ the ethane mixing ratios are slightly below $1.5 \mathrm{ppb}$, decreasing to $0.2-0.25 \mathrm{ppb}$ at $45^{\circ}-60^{\circ} \mathrm{S}$. Blake and Rowland report for June 1985 at sea level similar results for the southern hemisphere, $0.28 \pm 0.04 \mathrm{ppb}$. However, their results for the northern hemisphere are slightly lower than the STRATOZ III data: around $1 \mathrm{ppb}$ at $45^{\circ}-50^{\circ} \mathrm{N}$ decreasing to $0.5-0.7 \mathrm{ppb}$ around $20^{\circ} \mathrm{N}$. Measurements made during different seasons [Singh and Salas, 1982; Rudolph and Ehhalt, 1981; Rudolph et al., 1982a; Bonsang and Lambert, 1985; Blake and Rowland, 1986] showed ethane mixing ratios averaging around 1.5-2.5 $\mathrm{ppb}$ at middle northern latitudes and around $0.25-0.5 \mathrm{ppb}$ for middle southern latitudes. There are only three significant exceptions. During measurements in September 1984, Blake and Rowland [1986] found ethane values as low as $0.86 \pm 0.21$ ppb between $30^{\circ}$ and $75^{\circ} \mathrm{N}$ and during March 1985 only 0.14 $\mathrm{ppb} \pm 0.07 \mathrm{ppb}$ for $10^{\circ}-50^{\circ} \mathrm{S}$. Rudolph et al. [1982a] observed unusually high ethane values of $3-4 \mathrm{ppb}$ between $10^{\circ}$ and 
TABLE 1. Results of NMHC Measurements Above Ground Level off the West Coast of Ireland: Average Mixing Ratios

\begin{tabular}{|c|c|c|c|c|c|c|c|}
\hline \multirow[b]{3}{*}{ Compound } & \multirow{2}{*}{\multicolumn{3}{|c|}{ Tille et al. [1985], 0-6 km }} & \multicolumn{4}{|c|}{ Rudolph et al. [1982b] } \\
\hline & & & & \multicolumn{2}{|c|}{ Early July 1981} & \multicolumn{2}{|c|}{ Late November 1980} \\
\hline & July 5, 1981 & July 7,1981 & July 8, 1981 & $1.2-2.5 \mathrm{~km}$ & $3.0-6.6 \mathrm{~km}$ & $0.3-2.5 \mathrm{~km}$ & $3.0-4.8 \mathrm{~km}$ \\
\hline $\mathrm{C}_{2} \mathrm{H}_{6}$ & $1.9 \pm 0.17$ & $1.7 \pm 0.24$ & $1.7 \pm 0.16$ & $1.3 \pm 0.2$ & $1.4 \pm 0.3$ & $4.3 \pm 0.8$ & $3.8 \pm 0.55$ \\
\hline $\mathrm{C}_{2} \mathrm{H}_{4}$ & $0.12 \pm 0.02$ & $0.24 \pm 0.06$ & $0.61 \pm 0.08$ & $0.54 \pm 0.17$ & $0.74 \pm 0.31$ & $2.4 \pm 1.0$ & $1.3 \pm 0.6$ \\
\hline $\mathrm{C}_{2} \mathrm{H}_{2}$ & $0.34 \pm 0.05$ & $0.14 \pm 0.03$ & $0.15 \pm 0.04$ & $0.08 \pm 0.02$ & $0.07 \pm 0.01$ & $0.51 \pm 0.2$ & $0.36 \pm 0.09$ \\
\hline $\mathrm{C}_{3} \mathrm{H}_{8}$ & $0.35 \pm 0.08$ & $0.17 \pm 0.02$ & $0.43 \pm 0.15$ & $0.11 \pm 0.04$ & $0.13 \pm 0.06$ & $1.75 \pm 0.63$ & $1.3 \pm 0.25$ \\
\hline $\mathrm{C}_{3} \mathrm{H}_{6}$ & $0.18 \pm 0.03$ & $0.2 \pm 0.08$ & $0.24 \pm 0.06$ & $0.26 \pm 0.04$ & $0.33 \pm 0.09$ & $0.46 \pm 0.15$ & $0.41 \pm 0.35$ \\
\hline$n-\mathrm{C}_{4} \mathrm{H}_{10}$ & $0.25 \pm 0.06$ & $0.10 \pm 0.01$ & $0.14 \pm 0.04$ & $0.02 \pm 0.01$ & $0.02 \pm 0.005$ & $0.53 \pm 0.15$ & $0.37 \pm 0.15$ \\
\hline$i-\mathrm{C}_{4} \mathrm{H}_{10}$ & $0.17 \pm 0.03$ & $0.09 \pm 0.03$ & $0.18 \pm 0.02$ & $0.02 \pm 0.005$ & $0.015 \pm 0.005$ & $0.16 \pm 0.02$ & $0.12 \pm 0.05$ \\
\hline$n-\mathrm{C}_{5} \mathrm{H}_{12}$ & $0.33 \pm 0.02$ & $0.30 \pm 0.09$ & $0.34 \pm 0.02$ & $\mathrm{p}^{*}$ & $\mathrm{p}^{*}$ & $0.11 \pm 0.03$ & $0.07 \pm 0.02$ \\
\hline$i-\mathrm{C}_{5} \mathrm{H}_{12}$ & $0.28 \pm 0.08$ & $0.08 \pm 0.02$ & $0.04 \pm 0.01$ & $\mathrm{p}^{*}$ & $\mathrm{p}^{*}$ & $1.5 \pm 0.7$ & $1.4 \pm 1.2$ \\
\hline
\end{tabular}

Mixing ratios are stated in ppb.

*Present in very low but detectable amounts.

$50^{\circ} \mathrm{N}$ in March-April 1981, which they ascribed to continental influence. In general, our ethane data from STRATOZ III are well within the range of other published ethane mixing ratios; most of the data are within a range of $\pm 30 \%$. Part of these slight differences may be due to systematic seasonal cycles, but random variations and differences in the absolute calibrations between the different authors also may contribute to the differences between the individual measurement series. Even slight but systematic longitudinal variations, as indicated by the small but significant differences between the northbound and southbound legs of the STRATOZ flights, cannot be ruled out.

\section{Acetylene}

The atmospheric lifetime of acetylene is still sufficiently long to expect mostly systematic latitudinal and altitudinal profiles. The results of Tille et al. [1985] and Rudolph et al. [1982b] for July 1981 (Table 1 ) at $52^{\circ} \mathrm{N}$ cover a wide range of acetylene mixing ratios, from 0.07 to $0.34 \mathrm{ppb}$, with an average of 0.16 ppb. Rudolph et al. [1984] observed acetylene mixing ratios of $0.6 \mathrm{ppb}$ in the lower troposphere, decreasing to $0.2 \mathrm{ppb}$ at the tropopause, over southern France in June 1979 at $44^{\circ} \mathrm{N}$. Comparable values of $0.23 \pm 0.06 \mathrm{ppb}$ were reported by Cronn and Robinson [1979] for the free troposphere, in April 1977, at $37^{\circ} \mathrm{N}$. Slightly higher levels, between 0.2 and $0.4 \mathrm{ppb}$, for acetylene were found at $70^{\circ} \mathrm{N}$ in May 1982 in the lower and middle troposphere by Rasmussen et al. [1983].

The measurements by Cronn and Robinson [1979] in the free troposphere at $9^{\circ} \mathrm{N}$ are, with $0.08 \mathrm{ppb}$, considerably lower than the results from middle and high northern latitudes. Such strong latitudinal gradients were also reported by other authors. During the GAMETAG flights in May 1978, Rasmussen and Khalil observed acetylene mixing ratios around 0.3 ppb at $30^{\circ}-35^{\circ} \mathrm{N}$, decreasing to $0.05-0.1 \mathrm{ppb}$ at tropical latitudes and to even lower values in the southern hemisphere. Very similar are the results of Rudolph and Ehhalt [1981] and Rudolph et al. [1982a, 1984] from acetylene measurements at surface level over the Atlantic. Between $40^{\circ}$ and $50^{\circ} \mathrm{N}$ their acetylene mixing ratios are $0.3-0.5 \mathrm{ppb}$, decreasing to $0.02-$ $0.04 \mathrm{ppb}$ in the southern hemisphere. Singh and Salas [1982] report comparable values around $0.4 \mathrm{ppb}$ for the northern hemisphere but surprisingly high acetylene mixing ratios of $0.1-0.3 \mathrm{ppb}$ for the southern hemisphere. With the exception of the southern hemispheric acetylene mixing ratios reported by Singh and Salas, these results are fully compatible with the measurements made during the STRATOZ III flights.

\section{Propane}

The variability shown by the propane mixing ratios is considerable, still the latitude-altitude profiles are systematic enough to serve as basis for quantitative comparisons. The propane mixing ratios measured by Tille et al. [1985], and Rudolph et al. [1982b] in July 1981 in the middle and lower troposphere vary between 0.11 and $0.43 \mathrm{ppb}$, with an average of $0.24 \mathrm{ppb}$ (Table 1). Quite similar results of $0.15-0.25 \mathrm{ppb}$ in the free troposphere were obtained by Rudolph et al. [1981b] for $44^{\circ} \mathrm{N}$ in June 1979. The propane measurements of Rasmussen et al. [1983], at $70^{\circ} \mathrm{N}$ showed mixing ratios of $0.4-0.5 \mathrm{ppb}$ above $1 \mathrm{~km}$ altitude and about half these values below $1 \mathrm{~km}$. Singh et al. [1986] observed quite similar propane mixing ratios over the Pacific at $40^{\circ} \mathrm{N}$, both in February 1985 and August 1984, however, the shapes of the vertical profiles differed. The profiles from February 1985 show a decrease of the propane mixing ratios from $0.5 \mathrm{ppb}$ at $2.5 \mathrm{~km}$ to $0.2 \mathrm{ppb}$ at 9.5 $\mathrm{km}$. The vertical gradient in the profile from August 1984 was reversed, with propane mixing ratios increasing from $0.2 \mathrm{ppb}$ at $2.5 \mathrm{~km}$ to $0.5 \mathrm{ppb}$ at $9.5 \mathrm{~km}$.

The latitudinal propane profiles reported in the literature [Bonsang and Lambert, 1985; Singh and Salas, 1982; Rudolph and Ehhalt, 1981; Rudolph et al., 1982a, 1984] show some variability but still allow definition of a reasonable range for the average propane mixing ratios in the two hemispheres. Northern hemispheric values range around $0.4-0.8 \mathrm{ppb}$, southern hemispheric mixing ratios are mostly $0.05-0.1 \mathrm{ppb}$. The southern hemispheric mixing ratios reported by Singh and Salas are higher, between 0.1 and $0.3 \mathrm{ppb}$. The published latitudinal and vertical profiles of propane compare favorably with our two-dimensional distributions.

\section{$C_{4}$ and $C_{5}$ Alkanes}

The atmospheric mixing ratios of the saturated $C_{4}$ and $C_{5}$ alkanes exhibit a very large, mostly unsystematic variability. Consequently, the results of different series of measurements can only be compared on a qualitative basis. The mixing ratios at middle northern latitudes are, both for measurements at sea level and vertical profiles, mostly between a tenth of a part per billion and a part per billion [Tille et al., 1985; Rudolph et al., 1982a, b; Bonsang and Lambert, 1985; Singh 
and Salas, 1982; Rudolph and Ehhalt, 1981]. However, values below $0.1 \mathrm{ppb}$ and of more than $1 \mathrm{ppb}$ also can sometimes be observed. In general, the $\mathrm{C}_{4}$ and $\mathrm{C}_{5}$ alkane mixing ratios in the southern hemisphere are lower, between some $10 \mathrm{ppt}$ to a few hundred parts per trillion. Our results from the STRATOZ III flights are comparable, but it is evident that the high variability of the $\mathrm{C}_{4}$ and $\mathrm{C}_{5}$ alkanes only allows comparison of the orders of magnitude of the $\mathrm{C}_{4}$ and $\mathrm{C}_{5}$ alkane mixing ratios.

\section{Ethene and Propene}

Both alkenes vary in mixing ratios by orders of magnitude, but with little indication of systematic trends. However, often the ethene and the propene mixing ratios run parallel to each other with an average ratio for ethene/propene of roughly $2: 1$ [Bonsang and Lambert, 1985; Rudolph et al., 1982a; Rudolph and Ehhalt, 1981; Bonsang et al., 1988]. This has also been found for the measurements of ethene and propene during the STRATOZ III flights. The absolute values for ethene vary from less than a tenth of a part per billion to more than a part per billion [cf. Tille et al., 1985; Rudolph et al., 1982a, b; Bonsang and Lambert, 1985; Rudolph and Ehhalt, 1981; Singh and Salas, 1982]. In general, the results from the STRATOZ III flights fall into this range of data. However, there is one large region with ethene and propene mixing ratios of more than $2 \mathrm{ppb}$ and $1 \mathrm{ppb}$, respectively, extending along the west coast of Africa between the equator and $40^{\circ} \mathrm{N}$. This not only requires large alkene sources in this region at ground level but also requires atmospheric mixing processes which cause a fast upward transport. Bonsang et al. [1988] observed even higher ethene and propene levels of several parts per billion at sea level off the east coast of Africa in April 1985. Furthermore, their results indicate that the atmospheric NMHC pattern directly reflects the concentration of the NMHCs in seawater, irrespective of the atmospheric lifetime of the individual hydrocarbons. This also points toward the existence of last mixing processes and agrees with the observation of high ethene and propene values in the middle and upper troposphere. Greenberg and Zimmermann [1984] observed an ethene mixing ratio of $4 \mathrm{ppb}$ and a propene mixing ratio of $0.45 \mathrm{ppb}$ in a sample collected at roughly $10^{\circ} \mathrm{S}$ in the atmosphere over the Pacific close to the Peruvian coast. They explained these values by oceanic emissions from the Peruvian upwelling zones. Furthermore, the results of Rasmussen and Khalil [1982], from ethene measurements in and above the boundary layer over the Pacific gave an estimated relative concentration difference across the boundary layer of only $20 \%$. The $90 \%$ confidence limits showed that this difference is more than $-5 \%$ and less than $50 \%$.

\section{Conclusions}

The presented results cover a number of light NMHCs with atmospheric lifetimes ranging from less than 1 day to several months. The results obtained for ethane, and to some extent also for propane and acetylene, can be considered as globally representative two-dimensional distributions. On the average, the random variation for ethane is about $\pm 30 \%$, for propane and acetylene already about a factor of 2 . This does not include systematic seasonal variations or the effect of local sources. For the shorter lived NMHCs, the $\mathrm{C}_{4}$ and $\mathrm{C}_{5}$ alkanes, and the light alkenes, it is not possible to define an averaged or representative latitude-altitude profile on the basis of the currently available data. The observed two- dimensional distributions for these short-lived species should be considered as pictures of a certain, momentary situation, strongly depending on latitude and longitude, regional sources, and transport conditions. Consequently, the measured latitude-altitude cross sections can be used as indicators both for the existence and magnitude of ground-level sources and for transport mechanisms. The observation of high mixing ratios of short-lived NMHCs over several regions in the middle and upper troposphere not only requires strong ground-level sources in these areas but also proves the existence of fast vertical mixing processes between the boundary layer and the free troposphere with time scales comparable to, or even shorter than, the atmospheric residence time of these species. The observed weak vertical gradients for the $\mathrm{C}_{4}$ and $\mathrm{C}_{5}$ alkanes and the light alkenes cannot be reconciled with the predictions from conventional one-dimensional models of a decrease in mixing ratios by orders of magnitude between ground level and the upper troposphere [Kasting and Singh, 1986; Fishman and Carney, 1984; Chameides and Cicerone, 1978; Brewer et al., 1983].

The large variability which is observed for the reactive, short-lived NMHCs has another consequence. There are several regions in the free troposphere with NMHC mixing ratios high enough that the atmospheric turnover of the reactive NMHCs by far exceeds the photochemical oxidation rate of methane. This not only indicates that even in the free troposphere the atmospheric photochemistry sometimes can be substantially influenced by NMHCs. It also raises the question to which extent this may favor the formation of products from reactions which require the participation of more than one intermediate NMHC oxidation product, e.g., the formation of organic peroxides.

The presented data cover only one season and thus do not allow identification of systematic seasonal variations. Since these types of measurements allow a reasonably representative estimate of the tropospheric burden for the longerlived NMHCs, similar flight missions, but during other seasons, might help to identify and quantify systematic seasonal variations of the longer-lived NMHCs, ethane, propane, and acetylene.

Acknowledgments. The author thanks F. Karcher from EERM (Toulouse) who organized this flight and the other participants for their assistance during the flight and the flight preparations. Thanks are also due to F. X. Meixner, A. Khedim, and A. Volz, for their contribution to the organization of this flight. F. J. Johnen, S. Diederich, and M. Zimmermann helped with the installation of the experiment in the airplane. I also thank the airplane's crew from the Centre d'Essais en Vol at Bretigny sur l'Orge. This work was supported financially by the Bundesminister für Forschung und Technologie of the Federal Republic of Germany.

\section{REFERENCES}

Blake, D. R., and F. S. Rowland, Global atmospheric concentrations and source strength of ethane, Nature, 321, 231-233, 1986.

Bonsang, B., and G. Lambert, Nonmethane hydrocarbons in an oceanic atmosphere, J. Atmos. Chem., 2, 257-271, 1985.

Bonsang, B., M. Kanakidou, G. Lambert, and P. Monfray, The marine source of $\mathrm{C}_{2}-\mathrm{C}_{6}$ aliphatic hydrocarbons, J. Atmos. Chem., 6 , 3-20, 1988.

Brewer, D. A., T. R. Augustson, and J. S. Levine, The photochemistry of anthropogenic nonmethane hydrocarbons in the troposphere, $J$. Geophys. Res., 88, 6683-6695, 1983.

Chameides, W. L., and R. J. Cicerone, Effects of nonmethane hydrocarbons in the atmosphere, J. Geophys. Res., 83, 947-952, 1978. 
Chatfield, R. B., and P. J. Crutzen, Sulfur dioxide in remote oceanic air: Cloud transport of reactive precoursers, J. Geophys. Res., 89, 7111-7132, 1984.

Cronn, D., and E. Robinson, Tropospheric and lower stratospheric vertical profiles of ethane and acetylene, Geophys. Res. Lett., 6, 641-644, 1979.

Davis, D. D., S. Fischer, R. Schiff, R. T. Watson, and W. Bollinger, A kinetics study of the reaction of $\mathrm{OH}$ radicals with two $\mathrm{C}_{2}$ hydrocarbons: $\mathrm{C}_{2} \mathrm{H}_{4}$ and $\mathrm{C}_{2} \mathrm{H}_{2}$, J. Chem. Phys., 63, 1707-1742, 1975.

Ehhait, D. H., and J. Rudolph, On the importance of light hydrocarbons in multiphase atmospheric systems, Ber. Kernforschungsanlage Jülich, JÜL-1942, pp. 1-43, 1984.

Ehhalt, D. H., J. Rudolph, F. X. Meixner, and U. Schmidt, Measurements of selected $C_{2}-C_{5}$ hydrocarbons in the background troposphere: Vertical and latitudinal variations, J. Atmos. Chem., 3, 29-52, 1985.

Esaias, W. E., G. C. Feldman, C. R. McClain, and J. A. Elrod, Monthly satellite-derived phytoplankton pigment distribution for the North Atlantic Ocean basin, Eos Trans. $A G U, 67,835-837$, 1986.

Fishman, J., and T. A. Carney, A one-dimensional photochemical model of the troposphere with planetary boundary layer parameterization, J. Atmos. Chem., I, 351-376, 1984.

Fishman, J., F. M. Vokovich, and E. V. Browell, The photochemistry of synoptic-scale ozone synthesis: Implications for the global tropospheric ozone budget, J. Atmos. Chem., 3, 299-320, 1985.

Fleming, R. H., The influence of hydrographic conditions on the behaviour of fish, FAO Fisheries Bull., 9, 181-196, 1956.

Gidel, L. T., Cumulus cloud transport of transient tracers, J. Geophys. Res., 88, 6587-6599, 1983.

Greenberg, J. P., and P. R. Zimmermann, Nonmethane hydrocarbons in remote tropical, continental and marine atmospheres, $J$. Geophys. Res., 89, 4767-4778, 1984.

Greenberg, J. P., P. R. Zimmermann, L. Heidt, and W. Pollock, Hydrocarbon and carbon monoxide emissions from biomass burning in Brasil, J. Geophys. Res., 89, 1350-1354, 1984.

Isaksen, I. S. A., O. Hov, S. A. Penkett, and A. Semb, Model analysis of measured concentration of organic gases in the Norwegian Arctic, J. Atmos. Chem., 3, 3-27, 1985.

Kasting, J. F., and H. B. Singh, Nonmethane hydrocarbons in the troposphere: Impact on the odd hydrogen and odd nitrogen chemistry, J. Geophys. Res., 91, 13,239-13,256, 1986.

Michael, J. V., D. F. Nava, R. P. Borkowski, W. A. Payne, and L. J. Stief, Pressure dependence of the absolute rate constants for the reaction $\mathrm{OH}+\mathrm{C}_{2} \mathrm{H}_{2}$ from 228-473K, J. Chem. Phys., 73, 67086776, 1980.

Nelson, P. F., S. M. Quigley, and M. Y. Smith, Sources of atmospheric hydrocarbons in Sidney: A quantitative determination using a source reconciliation technique, Atmos. Environ., 17, 439-449, 1983.

Rasmussen, R. A., and M. A. K. Khalil, Latitudinal distributions of trace gases in and above the boundary layer, Chemosphere, 11, 227-235, 1982.

Rasmussen, R. A., M. A. K. Khalil, and R. J. Fox, Altitudinal and temporal variation of hydrocarbons and other tracers of Arctic trace, Geophys. Res. Lett., I0, 144-147, 1983.

Rudolph, J., and D. H. Ehhalt, Measurements of $C_{2}-C_{5}$ hydrocarbons over the North Atlantic, J. Geophys. Res., 86, 11,95911,964, 1981.

Rudolph, J., D. H. Ehhalt, A. Khedim, and C. Jebsen, Determination of $C_{2}-C_{5}$ hydrocarbons in the atmosphere at low parts per $10^{9}$ to high parts per $10^{12}$ levels, J. Chromat., 217, 301-310, $1981 a$.

Rudolph, J., D. H. Ehhalt, and A. Tönnissen, Vertical profiles of ethane and propane in the stratosphere, J. Geophys. Res., 86, 7267$7272,1981 b$.

Rudolph, J., D. H. Ehhalt, U. Schmidt, and A. Khedim, Vertical distributions of some $C_{2}-C_{5}$ hydrocarbons in the nonurban troposphere, paper presented at 2 nd Symposium on Composition of the Nonurban Troposphere, Am. Meteorol. Soc., Boston, Mass., $1982 a$.

Rudolph, J., D. H. Ehhalt, A. Khedim, and C. Jebsen, Latitudinal profiles of some $C_{2}-C_{5}$ hydrocarbons in the clean troposphere over the Atlantic, paper presented at 2nd Symposium on Composition of the Nonurban Troposphere, Am. Meteorol. Soc., Boston, Mass., $1982 b$.

Rudolph, J., C. Jebsen, A Khedim, and F. J. Johnen, Measurements of the latitudinal distribution of light hydrocarbons and halocarbons over the Atlantic, in Proceedings of the 3rd European Symposium on Physico-Chemical Behaviour of Atmospheric Pollutants, edited by B. Versine and G. Aneletti, pp. 492-501, D. Reidel, Hingham, Mass., 1984.

Rudolph, J., F. J. Johnen, and A. Khedim, Problems connected with the analysis of halocarbons in the non-urban atmosphere, Int. J. Environ. Anal. Chem., 27, 97-122, 1986.

Rudolph, J., B. Vierkorn-Rudolph, and F. X. Meixner, Large-scale distribution of peroxyacetylnitrate: Results from the STRATOZ III flights, J. Geophys. Res., 92, 6653-6661, 1987.

Singh, H. B., and L. J. Salas, Measurement of selected light hydrocarbons over the Pacific Ocean: Latitudinal and seasonal variations, Geophys. Res. Lett., 9, 842-845, 1982.

Singh, H. B., L. J. Salas, and W. Viezee, The global distribution of peroxyacetyl nitrate, Nature, 321, 588-591, 1986.

Tille, K. J. W., M. Savelsberg, and K. Bächmann, Airborne measurements of nonmethane hydrocarbons over western Europe: Vertical distribution, seasonal cycles of mixing ratios and source strength, Atmos. Environ., 11, 1751-1760, 1985.

Volz, A., D. H. Ehhalt, and R. G. Derwent, Seasonal and latitudinal variation of ${ }^{14} \mathrm{CO}$ and the tropospheric concentration of $\mathrm{OH}$ radicals, J. Geophys. Res., 86, 5163-5171, 1981.

J. Rudolph, Institut für Atmosphärische Chemie, Kernforschungsanlage Jülich GmbH, Postfach 1913, D-5170 Jülich, Federal Republic of Germany.

(Received November 5, 1987; revised February 17, 1988; accepted February 17, 1988.) 